University of Nebraska - Lincoln

DigitalCommons@University of Nebraska - Lincoln

Faculty Publications, Department of Psychology

Psychology, Department of

December 2001

\title{
Individual differences in behavioral responses to novelty and amphetamine self-administration in male and female rats
}

\author{
J. E. Klebaur \\ University of Michigan-Ann Arbor
}

Rick A. Bevins

University of Nebraska-Lincoln, rbevins1@unl.edu

T. M. Segar

University of Kentucky

M. T. Bardo

University of Kentucky

Follow this and additional works at: https://digitalcommons.unl.edu/psychfacpub

Part of the Psychiatry and Psychology Commons

Klebaur, J. E.; Bevins, Rick A.; Segar, T. M.; and Bardo, M. T., "Individual differences in behavioral responses to novelty and amphetamine self-administration in male and female rats" (2001). Faculty Publications, Department of Psychology. 36.

https://digitalcommons.unl.edu/psychfacpub/36

This Article is brought to you for free and open access by the Psychology, Department of at DigitalCommons@University of Nebraska - Lincoln. It has been accepted for inclusion in Faculty Publications, Department of Psychology by an authorized administrator of DigitalCommons@University of Nebraska - Lincoln. 
Klebaur JE, Bevins RA, Segar TM, \& Bardo MT (2001) Individual differences in behavioral responses to novelty and amphetamine selfadministration in female and male rats. From Behavioural Pharmacology, 12, 267-275. Published by Lippincott Williams \& Wilkins; copyright (c) 2001 Lippincott Williams \& Wilkins. Used by permission. 


\title{
Individual differences in behavioral responses to novelty and amphetamine self-administration in male and female rats
}

\author{
J.E. Klebaur ${ }^{a}$, R.A. Bevins ${ }^{b}$, T.M. Segar ${ }^{c}$ and M.T. Bardo ${ }^{c}$ \\ ${ }^{a}$ Department of Psychology and Neuroscience Program, University of Michigan, Ann Arbor, Michigan, USA; ${ }^{b}$ Depart- \\ ment of Psychology, University of Nebraska-Lincoln, Lincoln, Nebraska, USA; ${ }^{\circ}$ Department of Psychology, University \\ of Kentucky, Lexington, Kentucky, USA
}

Correspondence to M.T. Bardo, 115 Kastle Hall, Lexington, KY 40506-0044, USA. E-mail: mbardo@pop.uky.edu

Received 21 March 2000; accepted as revised 25 April 2001

\begin{abstract}
Previous work has shown that individual differences in locomotor activity in an inescapable novel environment can predict acquisition of amphetamine self-administration. The current study examined whether individual differences in approach to novelty in a free choice test could also predict amphetamine self-administration. Further, the current study examined whether individual differences in either free choice or inescapable novelty tests could predict responding for a nondrug reinforcer (sucrose) in the presence and absence of amphetamine. Male and female rats were first tested for their response to free choice novelty (playground maze and novelty-induced place preference tests) and inescapable novelty. They were then tested for acquisition of sucrose-reinforced responding, amphetamine-induced changes in maintenance of sucrose-reinforced responding, and amphetamine self-administration. Based on the inescapable novelty test, acquisition of sucrose-reinforced responding was more rapid in male high responders (HR) compared to low responders (LR). This effect in males did not generalize to females. None of the novelty tests predicted the ability of amphetamine to decrease sucrose-maintained responding. However, using the inescapable novelty test, both male and female HRs self-administered more amphetamine than LRs within the dose range tested $(0.03-0.16 \mathrm{mg} / \mathrm{kg} / \mathrm{infusion})$. Neither the playground maze nor the novelty-induced place preference test predicted amphetamine self-administration. These results indicate that responses to free choice novelty and inescapable novelty predict different components of amphetamine-induced behavior. (c) 2001 Lippincott Williams \& Wilkins.
\end{abstract}

Keywords: individual differences, novelty, locomotor activity, amphetamine, self-administration, rat

\section{INTRODUCTION}

Previous research in the human drug abuse field has sought to identify factors that might predict an individual's susceptibility to drug use. Examination of factors such as risk taking and sensation seeking has shown a correlation between sensation seeking and high risk behavior, including drug use behavior (Cherpitel, 1993; Schafer et al., 1994; Zuckerman, 1994).

Correlations between sensation seeking and drug use behaviors have also been examined in animals. For example, Piazza et al. (1989) exposed a random sample of rats individually to a novel open-field environment. Using a median split of the sample, each rat was categorized as either a high responder (HR) or low responder (LR) based on its level of activity in the novel environment. Rats were then tested for acquisition of amphetamine self-adminis- tration. HR rats acquired self-administration more readily than $L R$ rats, suggesting that individual differences in vulnerability to drug use may be predicted from the behavioral response in a novel environment.

Similar research has also shown that individual differences in response to novelty can predict other drug effects in animals. For example, relative to LR rats, HR rats show enhanced sensitivity to the locomotor effects of amphetamine (Hooks et al., 1991, 1992b), morphine (Deroche et al., 1993), cocaine (Hooks et al., 1992a), and caffeine (Hooks et al., 1992a). HR rats also show greater sensitivity than LR rats to the amphetamine-induced disruption of food-maintained operant responding (Bevins et al., 1997). However, HR rats do not show a uniformly enhanced response to stimulant drugs; for example, the discriminative stimulus effects of amphetamine 
have been reported to be reduced or unchanged in HR rats compared to LR rats (Exner and Clark, 1993; Bevins et al., 1997).

While it appears that responses to a novel environment and drugs of abuse may be linked, categorization of rats into $H R$ and $L R$ groups is based on forced exposure to an inescapable novel environment. Previous work has shown that HR rats have a more prolonged secretion of corticosterone than LR rats when exposed to a novel environment (Piazza et al., 1991), suggesting that this test may reflect a stress response rather than a true exploratory response. It has been argued that free choice preference for novelty may be a better analog of 'sensation seeking' or novelty seeking (Bardo et al., 1996). In this test, animals are allowed free choice access to both novel and familiar stimuli. Using a free choice test to categorize rats as either high or low novelty seekers, it was found that high novelty seekers show greater amphetamine-conditioned place preference than low novelty seekers (Robinet et al., 1998; Klebaur and Bardo, 1999). Another report found that high novelty seekers are more sensitive than low novelty seekers to the rate suppressant effects of amphetamine in a drug discrimination test (Bevins et al., 1997).

Much of the research examining individual differences in response to drugs has been conducted using male rats. It has been shown that female rats behave differently from male rats in response to stimulant drugs. For example, females show greater and longer lasting increases in locomotor activity and behavioral stereotypies when challenged with amphetamine (Beatty and Holzer, 1978; Savageau and Beatty, 1981). High doses of amphetamine induce a greater amount of rotational behavior in females compared to males (Robinson et al., 1980; Robinson, 1984). Females also show a greater locomotor response to cocaine (van Haaren and Meyer, 1991), and acquire cocaine self-administration more rapidly than males (Lynch and Carroll, 1999). However, it is not known if response to novelty can predict differences in response to amphetamine in females compared to males.

The main purpose of the present study was to determine whether individual differences in response to novelty (either inescapable or free choice tests) specifically predict amphetamine self-administration, or whether these individual differences also predict response to a nondrug reinforcer (sucrose). In addition, we wanted to determine whether the novelty-induced differences that have been reported in the acquisition of amphetamine self-administration using a single unit dose can be seen during maintenance of self-administration across different doses. Finally, we wanted to determine whether these differences generalize across males and females.

\section{METHODS}

\section{Subjects}

Naive male, $200-225 \mathrm{~g}(n=44)$, and female, 150-175 g $(n=69)$, Sprague-Dawley rats were used. Male and female rats were run in separate experiments at different times. However, the methods in both experiments were identical except where noted below. Rats were housed individually with access to continuous food, except as noted below. Water was available continuously in the home cage.

\section{Apparatus}

The playground maze was a circular platform made from $\frac{3}{4}$-inch plywood painted flat black. The maze was $100 \mathrm{~cm}$ in diameter and was raised $55 \mathrm{~cm}$ above the floor. Eight hard plastic objects were secured to the maze with Velcro $20 \mathrm{~cm}$ from the edge, equally spaced from each other. The objects were a yellow block $(6 \times 6 \times 6 \mathrm{~cm})$, a purple toy razor $(6 \times 10 \times$ $5 \mathrm{~cm}$ ), a pink rabbit (about $7.5 \times 9 \times 6.5 \mathrm{~cm}$ ), a green monster (about $9 \times 7.5 \times 6.5 \mathrm{~cm}$ ), a Fisher-Price man (about $5 \times 9.5 \times 5 \mathrm{~cm}$ ), a baker man (about $8.5 \times 12$ $\times 7 \mathrm{~cm}$ ), a purple dinosaur (about $5 \times 7 \times 6.5 \mathrm{~cm}$ ), and a miniature building (about $7.5 \times 7.5 \times 4 \mathrm{~cm}$ ). The novel object used on the test day was an orange tiger (about $4.5 \times 4.5 \times 8.5 \mathrm{~cm}$ ). A video camera was suspended from the ceiling above the maze to record the rat's behavior on the familiarization days and test day.

The place preference apparatus consisted of a rectangular wooden chamber that had three different compartments separated by removable walls. Each end compartment had the dimensions of $29 \times$ $23 \times 45 \mathrm{~cm}(1 \times \mathrm{w} \times \mathrm{h})$. One end compartment had white walls, a wire mesh floor $(13 \times 13 \mathrm{~mm})$, and pine bedding beneath the floor. The other end compartment had black walls, a grid floor ( 15 rods, $6 \mathrm{~mm}$ in diameter), and cedar bedding beneath the floor. The middle compartment had the dimensions of $19 \times 24 \times 45 \mathrm{~cm}$, with gray walls and a solid wood floor. The walls separating the end compartments from the middle compartment could be removed and replaced with similar walls containing an opening $(10.5 \times 10.5 \mathrm{~cm})$ to allow access to all compartments on the preference test day. A video camera was suspended from the ceiling to record the rat's behavior.

Med Associates (St. Albans, VT, USA) operant boxes had inside dimensions of $28 \times 21 \times 20.9 \mathrm{~cm}$. Each box had a rod floor, stainless-steel end walls, 
and clear Plexiglas ${ }^{R}$ side walls and ceiling, and was enclosed in a sound attenuating chamber. A food hopper, $5 \times 4.2 \mathrm{~cm}$, was situated in the bottom center of the front panel and there was a metal lever on each side of the food hopper. A $28 \mathrm{~V}$ cue light, $3 \mathrm{~cm}$ in diameter, was centered $6 \mathrm{~cm}$ above each lever. A personal computer with Med Associate interfacing controlled experimental sessions.

\section{Procedure}

\section{Novelty tests}

All rats were screened by a single 'blind' observer in each of the following tests in the same order: (1) playground maze; (2) inescapable locomotor test; and (3) place preference test. The general procedures have been described previously for the playground maze (Nicholls et al., 1992), the locomotor test (Bevins et al., 1997) and the place preference test (Bevins et al., 1997). Previous work from our laboratory has shown a high correlation among different independent observers for these measures (Bevins et al., 1997).

All rats were habituated to the playground maze on each of three consecutive days. On these familiarization days, each rat was initially placed in the middle of the maze facing away from the experimenter and allowed to explore the maze for $3 \mathrm{~min}$. The position of the objects was kept constant for all rats on a single familiarization day, but was changed on a daily basis in order to prevent a position bias. Objects were wiped down with isopropyl alcohol after each trial.

On the day after the last familiarization trial, rats were tested for their approach to a novel object placed on the maze. For this test, rats were placed on the playground maze for another $3 \mathrm{~min}$ familiarization trial, and then they were removed and placed in their cage while remaining in the room for $1 \mathrm{~min}$. During this time, one object was removed and replaced by the novel object; the position of the object varied among the rats. For the novelty seeking test, rats were placed back on the maze facing away from the novel object and were allowed to explore the maze for $3 \mathrm{~min}$. Rats were classified as high or low novelty seekers based on a median split of their duration (seconds) of contact with the novel object on the playground maze. Contact with the object was operationally defined as the duration (seconds) of time the rat had its nose in a circular area, $14 \mathrm{~cm}$ in diameter, around each object.

Next, all rats were tested for locomotor response in an inescapable novel environment and noveltyinduced place preference. For the locomotor test, rats were confined to the white compartment of the place preference apparatus for $30 \mathrm{~min}$ and horizontal and vertical activity was recorded. Horizontal activity was operationally defined by both front paws crossing a line drawn on a video monitor screen that bisected the compartment parallel to the partitioning walls. Vertical activity was operationally defined by both front paws off of the floor, excluding grooming movements. Following this, rats were placed in the white compartment for $30 \mathrm{~min}$ on a second day as part of the novelty-induced place preference test. On the third day, rats were given a preference test. Rats were placed in the center compartment and given free access to the entire place preference apparatus for $15 \mathrm{~min}$. The duration (seconds) spent in each compartment was recorded as a measure of novelty preference.

\section{Acquisition of responding reinforced by sucrose}

Following completion of the novelty tests, food was removed from the home cage of each rat. The body weight of each rat was then gradually reduced to $80 \%$ for males or $85 \%$ for females of their free feeding body weight. Once rats reached this body weight, magazine training began. One lever (balanced across rats) was mounted in the operant chamber and spontaneous responses resulted in delivery of a sucrose pellet $(45 \mathrm{mg})$. On the following day, rats were shaped to depress the lever. Across days, the fixed ratio (FR) response requirement was gradually increased from an FR-1 to an FR-25 until responding stabilized. The criteria for stable responding consisted of two consecutive days of 20 or more sucrose reinforcers earned during the $15 \mathrm{~min}$ session and less than $15 \%$ variability between the 2 days in the number of reinforcers earned.

\section{Amphetamine disruption of responding maintained by sucrose}

Once rats reached an FR-25, they were assessed for the dose-dependent effect of amphetamine on sucrose-maintained responding. D-Amphetamine sulfate $(0,0.3,1.0$ and $3.0 \mathrm{mg} / \mathrm{kg}$, i.p. $)$ in a saline vehicle was administered $15 \mathrm{~min}$ prior to the session, in a counterbalanced order of doses with at least two sessions intervening between each test injection. Amphetamine test injections were only administered when rats displayed a stable response pattern.

\section{Amphetamine self-administration}

Finally, rats were assessed for amphetamine self-administration. Rats were anesthetized with ketamine $(80 \mathrm{mg} / \mathrm{kg}$, i.p.) and diazepam $(5 \mathrm{mg} / \mathrm{kg}$, i.p.) and a silastic catheter, to which a metal cannula was attached, was inserted into the jugular vein. The can- 
nula exited through the skin and was secured to a head mount. Rats were allowed to recover from surgery for 5-6 days. During recovery, the catheter of each rat was flushed twice daily, once in the morning with gentamicin $(40 \mathrm{mg} / \mathrm{ml})$ and once in the afternoon with streptokinase (750000 IU mixed in $0.9 \%$ sterile sodium chloride).

Rats were allowed to self-administer a single dose of D-amphetamine sulfate $(0.1 \mathrm{mg} / \mathrm{kg} /$ infusion $)$ on a FR-1/20s time-out (TO 20") schedule of reinforcement daily during a 3-hour session. During these sessions, the cannula was connected to an infusion pump while animals were in the operant chamber equipped with two levers. Depressing one lever (balanced across rats) delivered $0.1 \mathrm{ml}$ of drug solution over a $5.5 \mathrm{~s}$ interval. Depressing the other lever did not result in delivery of an infusion. For males, the FR ratio was increased by 1 every third day until an FR-5 was reached. For females, the FR ratio was increased by 1 daily, based upon preset criteria of earning 10 or more infusions and responding at $80 \%$ or greater on the appropriate lever. In both males and females, once an FR-5/TO 20" schedule of reinforcement was reached, stable responding was established. Stable responding was defined as three consecutive sessions of responding on the drug-appropriate lever with less than $15 \%$ variability in the number of infusions earned. Following this, rats were tested during individual sessions for self-administration of different amphetamine doses $(0.03$ and $0.16 \mathrm{mg} / \mathrm{kg} /$ infusion) on a FR-5/TO 20". After each test dose, rats were returned to the training dose until a stable baseline (two consecutive sessions with less than $15 \%$ variability in the number of infusions earned) was re-established. Following the last self-administration session, the patency of the catheter was verified by infusing morphine $(15 \mathrm{mg} / \mathrm{kg})$ into the catheter. The catheter was considered patent if the morphine produced rapid ataxia.

\section{Data analysis}

Since males and females were run using different training procedures at separate times, the data were treated as two experiments and analyzed separately from one another without sex as a variable. For the phases of lever press training and amphetamine-disrupted responding, each individual novelty test was subjected to a median-split procedure in which each rat was classified as either a high (above the median) or low (below the median) responder. If the rat's score was equal to the median, it was eliminated from the analyses. Each dependent measure was analyzed separately using a two-way analysis of variance (ANOVA), with the median-split category (high versus low) as a between-subjects factor and amphetamine dose as a within-subjects factor, where appropriate. For the amphetamine self-administration phase, the data obtained from the training dose $(0.1 \mathrm{mg} / \mathrm{kg} /$ infusion) across the three sessions that defined stable responding were analyzed as a threeway ANOVA, with the median-split group (high versus low) as a between-subjects factor, and session and lever (active versus inactive) as within-subjects factors. To assess the effect of varying the amphetamine dose, a two-way ANOVA was used, with the median-split group (high versus low) as a between-subjects factor and amphetamine dose as a within-subjects factor. Only animals that completed the entire self-administration regimen and had patent catheters at the end of the experiment were used to derive the median-split in this latter analysis. Subsequent pairwise comparisons were made using Tukey's HSD test.

\section{RESULTS}

\section{Novelty tests}

The ranges of scores for each novelty test for males were as follows: playground maze $(2-32$, median $=$ 14); line crosses in inescapable novelty (29-126, median $=64)$; rears in inescapable novelty $(15-121$, median $=68$ ); and novelty-induced place preference $(105-516$, median $=297.5)$. The ranges of scores for each novelty test for females were as follows: playground maze $(0-33$, median $=10)$; line crosses in inescapable novelty $(24-119$, median $=58)$; rears in inescapable novelty $(9-116$, median $=54)$; and novelty-induced place preference $(27-572$, median $=346$ ).

Table 1 shows the correlations among the novelty tests for males and females. In the inescapable novelty test, there was a highly significant correlation between the number of horizontal line crosses and vertical rears in both males and females. Since these two measures in inescapable novelty were

TABLE 1. Correlations among novelty tests for males $(n=44)$ and females $(n=69)$

\begin{tabular}{lccc}
\hline & Line crosses $^{\mathrm{a}}$ & Rears $^{\mathrm{a}}$ & Place preference \\
\cline { 3 - 4 } & & & \\
Males & 0.21 & 0.16 & 0.01 \\
$\quad$ Playground maze & $0.57^{*}$ & -0.15 \\
Line crosses $^{\mathrm{a}}$ & & & -0.30 \\
$\quad$ Rears & & & \\
Females & & & 0.10 \\
$\quad \begin{array}{l}\mathrm{a} \\
\text { Playground maze }\end{array}$ & 0.10 & 0.06 & -0.09 \\
Line crosses $^{\mathrm{a}}$ & & $0.68^{*}$ & -0.09 \\
Rears $^{\mathrm{a}}$ & & & -0.13 \\
\hline
\end{tabular}

${ }^{a}$ Line crosses and rears were both obtained in the inescapable novelty test.

Significant correlation, $P<0.05$. 
highly correlated, they were combined into a single measure of locomotor activity in subsequent analyses. The only other effect that reached statistical significance was a negative correlation between rears in the inescapable novel environment and preference for novelty in the place preference test. That is, rats that reared more in the inescapable novelty test spent less time in the novel chamber during the place preference test. However, this correlation was significant only in males, not in females.

\section{Acquisition of responding reinforced by sucrose}

For males, the novelty scores from 1-4 rats (depending on the novelty test) fell on the median and thus were excluded from the median-split analysis. There were no differences in acquisition based on the playground maze or the novelty-induced place preference test. However, males classified as HRs based on the inescapable novel environment test took significantly less time than LRs to acquire FR performance $[F(1,42)=5.19, P<0.05]$. The mean $( \pm$ SEM $)$ number of days to reach acquisition criteria for $\mathrm{HR}$ and LR males was $15.3( \pm 1.1)$ and $20.0( \pm 1.7)$ respectively. Upon reaching criteria, there were no significant differences in number of active lever presses, regardless of the novelty test.

For females, the novelty scores from 1-8 rats (depending on the novelty test) fell on the median and thus were excluded from the median-split analysis. Unlike males, no significant differences in either acquisition or responding at stable criteria were obtained between females that were above or below the median-split, regardless of the novelty test.

\section{Amphetamine disruption of responding maintained by} sucrose

For males, regardless of the novelty test, there was a significant decrease in responding maintained by sucrose as the dose of amphetamine increased $(P<$ 0.001 in each median-split ANOVA). The effect of amphetamine did not differ between high or low novelty seeker males using either the playground maze or novelty-induced place preference test (data not shown). When males were classified as HR or LR based on the inescapable novel environment, there was no significant group difference, nor was there a significant group $\times$ dose interaction, indicating that HR and LR males showed a similar sensitivity to the response disruptive effect of amphetamine (Figure 1A).

For females, regardless of the novelty test, again there was a significant decrease in responding maintained by sucrose as the dose of amphetamine increased $(P<0.001$ in each median-split ANOVA).

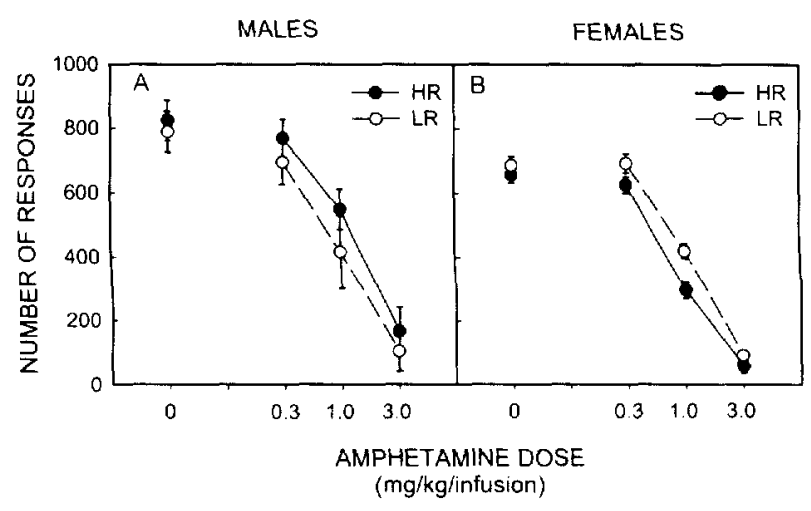

FIGURE 1. Mean ( \pm SEM) number of responses for sucrose on an FR-25 schedule of reinforcement for males ( $n=22$ per group; panel A) and females ( $n=30-31$ per group; panel B) classified as HR or LR based on inescapable novelty.

This effect of amphetamine did not differ between high or low novelty seeker females using either the playground maze or novelty-induced place preference test (data not shown). When females were classified as HR or LR based on the inescapable novel environment, there was no significant group difference, nor was there a significant group $\times$ dose interaction, indicating that $\mathrm{HR}$ and $\mathrm{LR}$ females showed a similar sensitivity to the response disruptive effect of amphetamine (Figure 1B).

\section{Amphetamine self-administration}

Since not all rats completed the amphetamine selfadministration phase of the experiment with patent catheters, new median-split analyses were performed based on the novelty scores using only the rats that completed this portion of the experiment. In these analyses, the novelty scores from 1-2 males and 2-4 females (depending on the novelty test) fell on the median and thus were excluded from the mediansplit analyses. The range of remaining scores for each novelty test for males was as follows: playground maze $(n=19,2-32$, median $=14)$; line crosses in inescapable novelty $(n=19,29-126$, median $=62)$; rears in inescapable novelty $(n=19$, $15-121$, median $=66$ ) and novelty-induced place preference $(n=19,184-516$, median $=328)$. The range of remaining scores for each novelty test for females was as follows: playground maze $(n=37$, $0-31$, median $=8$ ); line crosses in inescapable novelty $(n=37,29-119$, median $=59)$; rears in inescapable novelty ( $n=37,9-116$, median $=63$ ); and novelty induced place preference $(n=37,164-510$, median $=332$ ).

Using the training dose of $0.1 \mathrm{mg} / \mathrm{kg} /$ infusion, no significant differences in the number of sessions required to acquire stable FR-5 responding on the 
active lever were obtained in males or females categorized above or below the median-split, regardless of the novelty test (data not shown). However, when the stable criteria were met on the training dose, both males and females categorized as either HR and LR based on inescapable novelty displayed a difference in the number of infusions earned across the three sessions that defined stable responding. For males, there was a significant main effect of group $[\mathrm{F}(1,32)=6.51, P<0.05]$ and lever $[\mathrm{F}(1,32)=$ 400.04, $P<.001]$, as well as a significant group $\times$ lever interaction $[\mathrm{F}(1,32)=4.38, P<0.05]$. Pairwise comparisons of the results collapsed across the three sessions revealed that $\mathrm{HR}$ males responded more than LR males on the active lever, but not on the inactive lever (Figure 2A). For females, there was a significant main effect of group $[\mathrm{F}(1,41)=5.10, P<$ $0.05]$ and lever $[F(1,41)=38.98, P<0.001]$, but no significant group $\times$ lever interaction. Thus, regardless of the lever, the overall response rate was higher in HR females than LR females (Figure 2B). When rats were classified as high or low novelty seekers based on the either the playground maze or noveltyinduced place preference test, there were no significant differences in the number of responses on the active or inactive levers across the three sessions of stable responding on the training dose of amphetamine for either males or females (data not shown).

Examination of the dose-effect results revealed that as the unit dose of amphetamine increased, there was a decrease in the number of infusions earned in both males and females. Regardless of sex, rats classified as high or low novelty seekers, based on the either the playground maze or novelty-induced place preference test, did not differ in num-

MALES

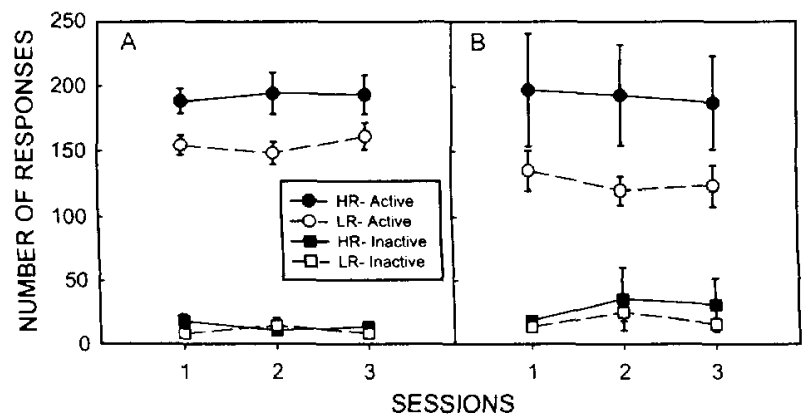

FIGURE 2. Mean ( \pm SEM) number of responses on the active and inactive levers across the three sessions at which stable responding for the training dose of amphetamine $(0.1 \mathrm{mg} / \mathrm{kg} /$ infusion) was obtained in males ( $n=9$ per group; panel A) and females ( $n=9-14$ per group; panel B) classified as HR or LR based on inescapable novelty.

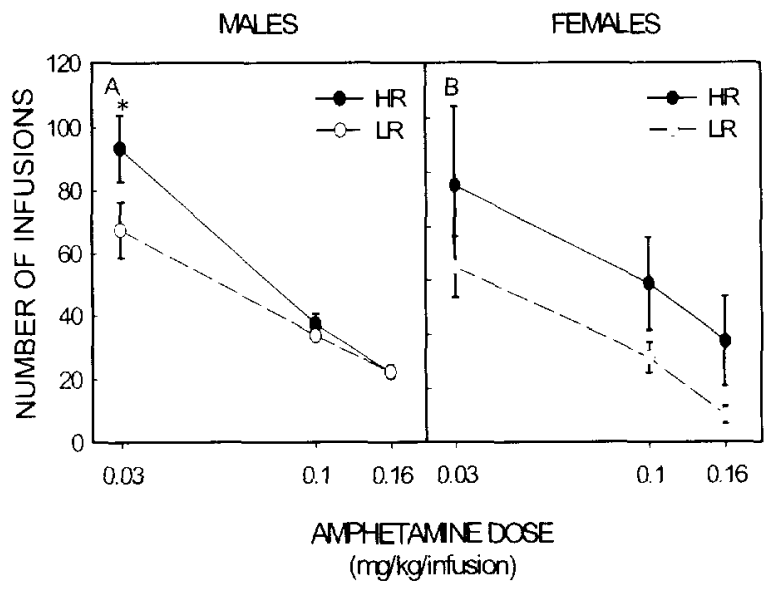

FIGURE 3. Mean ( \pm SEM) number of infusions across various unit doses of amphetamine for males ( $n=9$ per group; panel A) and females ( $n=9-14$ per group; panel B) classified as HR or LR based on inescapable novelty. The asterisk (*) represents a significant post-hoc difference between HR and LR males using a Tukey's test following a significant group $\times$ dose interaction, $P<0.05$

ber of infusions earned during the self-administration sessions (data not shown). In contrast, when males were classified as HR or LR based on inescapable novelty, there was a significant main effect of dose $[F(2,24)=127.25, P<0.001]$, as well as a significant dose $\times$ group interaction $[\mathrm{F}(2,24)=6.03$, $P<0.01]$. Subsequent pairwise comparisons showed that HR males earned more infusions than LR males at $0.03 \mathrm{mg} / \mathrm{kg}$ /infusion amphetamine, but not at either 0.1 or $0.16 \mathrm{mg} / \mathrm{kg}$ /infusion amphetamine (see Figure $3 \mathrm{~A}$ ); however, the Tukey's HSD comparison at the training dose $(0.1 \mathrm{mg} / \mathrm{kg} /$ infusion $)$ approached significance $(P<0.06)$. When females were classified as HR or LR based on activity in an inescapable novel environment, there was a significant main effect of dose $[\mathrm{F}(2,42)=18.79, P<0.001]$ and the main effect of group approached statistical significance $[F(1,21)=4.04, P<0.06]$, but there was no significant group $\times$ dose interaction. Tukey's tests at each dose revealed that HR females earned more infusions than LR females at the 0.1 and $0.16 \mathrm{mg} / \mathrm{kg}$ /infusion unit doses (see Figure 3B).

\section{DISCUSSION}

The purpose of this study was to further examine the ability of individual differences in response to novelty to predict the behavioral effects of amphetamine. This idea was based on previous work showing that individual differences in response to novelty predict acquisition of amphetamine self-administration, locomotor response to stimulants, and development of amphetamine sensitization (Piazza et al., 1989; 
Hooks et al., 1991, 1992b). The predictor variable used in these previous studies was based on the animal's response to an inescapable novel environment. Research also has shown that rats classified as HR based on their response to an inescapable novel environment have a more prolonged secretion of corticosterone than LR rats (Piazza et al., 1991); thus, this test likely reflects, at least in part, a stress response to the environment. To assess approach to novelty in a free choice test, we examined the ability of the playground maze and the novelty-induced place preference test, in addition to inescapable novelty, to predict individual differences in amphetamine-disrupted responding and amphetamine self-administration. These two tests have recently been shown to be sensitive to individual differences in amphetamine conditioned place preference (Robinet et al., 1998; Klebaur and Bardo, 1999).

A correlational analysis revealed that individual scores on the playground maze were unrelated to scores from the other novelty tests in both males and females. Horizontal activity measured in an inescapable novel environment was positively correlated with vertical activity in an inescapable novel environment in both males and females, but was not correlated with scores from either the playground maze or place preference test. These results are consistent with previous work showing that these novelty tests are not redundant measures of a common behavioral process (Bevins et al., 1997). However, an unexpected finding from the present report is that vertical activity in the inescapable novel environment test was negatively correlated with noveltyinduced place preference. One interpretation of this latter finding is that the tendency to emit rearing behavior may interfere with horizontal choice behavior in the novelty place preference apparatus.

It was also found that neither the playground maze nor the novelty-induced place preference test predicted individual differences in acquisition of an FR-25 for sucrose reinforcement for either males or females. However, males classified as HR based on an inescapable novel environment took significantly less time to acquire the task. There were no reliable differences in acquisition for the female rats based on any novelty test. These results suggest that free choice and inescapable novelty tests differentially predict acquisition of a sucrose reinforced response, but only in males. Although a direct statistical comparison between male and female rats in this study was not conducted because each sex was assessed in separate experiments, previous research suggests that male rats are typically more active than female rats when lever pressing (Millar, 1975; van Hest et al., 1987). In addition, male rats respond at higher rates than female rats during acquisition of a random ratio schedule of reinforcement (Heinsbroek et al., 1987), which may explain the differences in acquisition seen between male and female rats in this study.

It was also found that none of the novelty tests used predicted differences in the rate suppressant effects of amphetamine for either males or females. The failure to find a difference between HR and LR rats on this measure is not consistent with a previous report from our laboratory in which male HR rats were more sensitive to the rate suppressant effects of amphetamine (Bevins et al., 1997). However, this inconsistency could be explained by procedural differences. In the study of Bevins et al. (1997), while rats also were trained to respond on an FR-25 for sucrose reinforcement, they had an extensive number of repeated amphetamine injections as part of a drug discrimination paradigm. In contrast, the present study assessed rats after an acute injection of three different doses of amphetamine. Thus, the significant difference obtained by Bevins et al. (1997) may reflect individual differences in tolerance or sensitization to the rate suppressant effect of amphetamine across repeated injections.

For amphetamine self-administration, when males and females were classified as high or low novelty seekers based on either the playground maze or place preference test, there were no differences in amphetamine self-administration. However, using the inescapable novelty test, both male and female HR rats self-administered more amphetamine than LR rats, a finding that is consistent with the results of Piazza et al. (1989). While we did not find any differences in the rate of acquisition as reported by Piazza et al. (1989), this was probably due to procedural differences in assessing acquisition. Piazza et al. (1989) examined acquisition on a continuous schedule of reinforcement across 5 days, while we used a forced acquisition procedure in which the FR ratio increased across days. In addition, the rats in our study received substantial operant training prior to amphetamine self-administration.

In a recent study, Piazza et al. (2000) found that male HR rats exhibit a vertical shift in the doseeffect curve for cocaine self-administration, with $H R$ rats showing greater intake of cocaine relative to LR rats across all unit doses tested from 0.03 to $1 \mathrm{mg} / \mathrm{kg}$ /infusion. The current study extends this previous report by examining amphetamine self-administration in both males and females. Both male and female HR rats showed a higher self-infusion rate than $L R$ rats when responding stabilized on the 
training dose $(0.1 \mathrm{mg} / \mathrm{kg}$ /infusion). However, when doses above and below the training dose were tested, notable sex differences became evident. Lowering the test dose to $0.03 \mathrm{mg} / \mathrm{kg}$ /infusion enhanced the difference between HR and LR males, but did not do so for female rats. Female rats also earned overall fewer infusions than males at this lower dose. Although more doses are needed to characterize fully the inverted U-shaped dose-effect curve that typifies stimulant self-administration on an FR schedule (Yokel, 1987), these results suggest that the peak of the dose-effect curve in females may be shifted to the left relative to males, perhaps reflecting a greater sensitivity to the reinforcing effect of amphetamine in females. This sex difference may relate to differences in levels of estrogen (Roberts $e t$ al., 1989; Grimm and See, 1997; Becker, 1999) or amphetamine metabolism (Becker et al., 1982). Regardless of the mechanism, however, the fact that amphetamine produced a similar decrease in sucrose-maintained responding in males and females, whether they were categorized as $\mathrm{HR}$ or LR, rules out the possibility that sex differences in amphetamine self-administration can be explained by differences in the rate suppressant effect of amphetamine.

Based on the results of this study, it appears that the ability to predict differences in amphetamine self-administration depends on the test used to assess individual differences in response to novelty. Tests such as the playground maze and novelty-induced place preference do not appear to predict group differences in amphetamine self-administration. However, these tests predict differences in the magnitude of amphetamine-conditioned place preference (Robinet et al., 1998; Klebaur and Bardo, 1999). Conversely, the inescapable novel environment test predicts differences in amphetamine selfadministration (Piazza et al., 1989; present results), but not amphetamine-conditioned place preference (Erb and Parker, 1994; Robinet et al., 1998; Klebaur and Bardo, 1999). The differences in the predictive ability of these novelty tests may be due to procedural differences between drug self-administration and conditioned place preference. Consistent with this, we have found that individual differences in amphetamine-conditioned place preference and selfadministration are dissociable effects (Bardo et al., 1999). In general, drug self-administration is thought to be acquired due to the primary reinforcing effect of the drug, and is considered to be the best laboratory model of drug-taking behavior (Yokel, 1987). Conditioned place preference is thought to reflect an approach to conditioned stimuli associated with the drug and may be a useful model of cue-elicited drug seeking behavior or craving in the absence of drug (Carr et al., 1989; Markou et al., 1993; Bardo et al., 1995). Therefore, it appears that activity in inescapable novelty may be a better predictor of the primary reinforcing effect of amphetamine, whereas preference for free choice novelty may be a better predictor of amphetamine-conditioned reinforcement.

Finally, previous research shows that motor activity in humans, as assessed by wrist movements, is sensitive to environmental factors and is increased following amphetamine administration (Greenwald et al., 1998). These results, as well as those from our study, suggest that motor activity in humans can be used to predict individual differences in response to novelty and drugs of abuse. This could possibly lead to more effective strategies in drug abuse prevention in humans.

\section{Acknowledgements}

Supported by USPHS grants DA05312 and DA12964.

\section{REFERENCES}

Bardo MT, Rowlett JK, Harris MJ (1995). Conditioned place preference using opiate and stimulant drugs: A meta-analysis. Neurosci Biobehav Rev 19:39-51.

Bardo MT, Donohew RL, Harrington NG (1996). Psychobiology of novelty seeking and drug seeking behavior. Behal Brain Res 77:23-43.

Bardo MT, Valone JM, Bevins RB (1999). Locomotion and conditioned place preference produced by acute intravenous amphetamine: Role of dopamine receptors and individual differences in amphetamine self-administration. Psychopharmacology 143:39-46.

Beatty WW, Holzer GH (1978). Sex differences in stereotyped behavior in the rat. Pharmacol Biochem Behai 9:777-783.

Becker JB (1999). Gender differences in dopaminergic function in striatum and nucleus accumbens. Pharmacol Biochem Behat 64:803-812.

Becker JB, Robinson TE, Lorenz KA (1982). Sex differences and estrous cycle variations in amphetamine-elicited rotational behavior. Eur J Pharmacol 80:65-72.

Bevins RA, Klebaur JE, Bardo MT (1997). Individual differences in response to novelty, amphetamine-induced activity and drug discrimination in rats. Behai Pharmacol 8:113-123.

Carr GD, Fibiger HC, Phillips AG (1989). Conditioned place preference as a measure of drug reward. In: The Neurophamacological Basis of Reward. Liebman JM, Cooper SJ (editors). Oxford: Clarendon, pp. 264-319.

Cherpitel CJ (1993). Alcohol, injury, and risk-taking behavior: Data from a national sample. Alcohol Clin Exp Res 17:762-766.

Deroche V, Piazza PV, Le Moal M, Simon H (1993). Individual differences in psychomotor effects of morphine are predicted by reactivity to novelty and influenced by corticosterone secretion. Brain Res 623:341-344.

Erb SM, Parker LA (1994). Individual differences in novelty-induced activity do not predict strength of amphetamine-induced place conditioning. Pharmacol Biochem Behat 48:581-586. 
M M, Clark D (1993). Behavior in the novel environment predicts responsiveness to $\mathrm{D}$-amphetamine in the rat: A multivariate approach. Behav Pharmacol 4:47-56.

Greenwald MK, Schuster CR, Johanson C, Jewell J (1998). Automated measurement of motor activity in human subjects: effects of repeated testing and D-amphetamine. Pharmacol Biochem Behai 59:59-65.

Grimm JW, See RE (1997). Cocaine self-administration in ovariectomized rats is predicted by response to novelty, attenuated by 17 -beta estradiol, and associated with abnormal vaginal cytology. Physiol Behal 61:755-761.

Heinsbroek RP, van Haaren F, Zantvoord F, van de Poll NE (1987). Sex differences in response rates during random ratio acquisition: effects of gonadectomy. Physiol Behar 39:269-272.

Hooks MS, Jones GH, Smith AD, Neill DB, Justice JB (1991). Individual differences inlocomotor activity and sensitization. Pharmacol Biochem Behal 38:467-470.

Hooks MS, Jones GH, Liem BJ, Justice JB (1992a). Sensitization and individual differences to IP amphetamine, cocaine or caffeine following repeated intracranial amphetamine infusions. Pharmacol Biochem Behai 43:815-823.

Hooks MS, Jones GH, Neill DB, Justice JB (1992b). Individual differences in amphetamine sensitization: dose-dependent effects. Pharmacol Biochem Behal 41:203-210.

Klebaur JE, Bardo MT (1999). Individual differences in novelty seeking on the playground maze predict amphetamine conditioned place preference. Pharmacol Biochem Behal 63:131-136.

Lynch WJ, Carroll ME (1999). Sex differences in the acquisition of intravenously self-administered cocaine and heroin in rats. Psychophamacology 144:77-82.

Markou A, Weiss F, Gold LH, Caine B, Schulteis G, Koob GF (1993). Animal models of drug craving. Psychopharmacology 112:163-182.

Millar RD (1975). Free-operant comparisons of wild and domestic Norway rats. J Comp Physiol Psychol 89:913-922.

Nicholls B, Springham A, Mellanby J (1992). The playgsound maze: a new method for measuring directed exploration in the rat. J Neurosci Methods 43:171-180.

Piazza PV, Deminiere J, Le Moal M, Simon H (1989). Factors that predict individual vulnerability to amphetamine self-administration. Science 245:1511-1513.
Piazza PV, Maccari S, Deminiere J, Le Moal M, Mormede P, Simon H (1991). Corticosterone levels determine individual vulnerability to amphetamine self-administration. Proc Natl Acad Sci 88:2088-2092.

Piazza PV, Deroche-Gamonent V, Rouge-Pont F, Le Moal M (2000). Vertical shifts in self-administration dose-response functions predict a drug-vulnerable phenotype predisposed to addiction. J Neurosci 20:4226-4232.

Roberts DCS, Bennett S, Vickers G (1989). The estrous cycle affects cocaine self-administration on a progressive ratio schedule in rats. Psychopharmacology 98:408-411.

Robinet PM, Rowlett J, Bardo MT (1998). Individual differences in novelty-induced activity and the rewarding effects of novelty and amphetamine in rats. Behar Process 44:1-9.

Robinson TE (1984). Behavioral sensitization: Characterization of enduring changes in rotational behavior produced by intermittent injections of amphetamine in male and female rats. Psychopharmacology 84:466-475.

Robinson TE, Becker JB, Ramirez VD (1980). Sex differences in amphetamine-elicited rotational behavior and the lateralization of striatal dopamine in rats. Brain Res Bull 5:539-545.

Savageau MM, Beatty WW (1981). Gonadectomy and sex differences in the behavioral responses to amphetamine and apomorphine of rats. Pharmacol Biochem Behal 14:17-21.

Schafer J, Blanchard L, Fals-Stewart W (1994). Drug use and risky sexual behavior. Psychol Addict Behal 8:3-7.

van Haaren F, Meyer ME (1991). Sex differences in locomotor activity after acute and chronic cocaine administration. Pharmacology Biochemistry and Behatior 39:923-927.

van Hest A, van Haaren F, van de Poll NE (1987). Behavioral differences between male and female Wistar rats on DRL schedules: effect of stimuli promoting collateral activities. Physiol Behat 39:255-261.

Yokel RA (1987). Intravenous self-administration: Response rates, the effects of pharmacological challenges, and drug preference. In: Methods of Assessing the Reinforcing Properties of Abused Drugs. Bozarth MA (editor). New York: SpringerVerlag, pp. 1-33.

Zuckerman M (1994). Behatioral Expressions and Biosocial Bases of Sensation Seeking. Cambridge: Cambridge University Press. 